\title{
Mobil Kontrol- Görüntü Aktarımı ve Lazer Savunma Gücüne Sahip Tank Robot Tasarımı
}

\author{
Burak Kapusız $^{1 *}$, Yusuf Uzun ${ }^{2}$ \\ 1* Necmettin Erbakan Üniversitesi, Fen Bilimleri Enstitüsü, Mekatronik Mühendisliği Ana Bilim Dalı, Konya, Türkiye, (ORCID: 0000-0003-1592-0240 ), \\ burak_kapusuz@hotmail.com
}

${ }^{2}$ Necmettin Erbakan Üniversitesi, Seydişehir Ahmet Cengiz Mühendislik Fakültesi, Bilgisayar Mühendisliği Bölümü, Konya, Türkiye, (ORCID: 0000-0002-70618784),yuzun@erbakan.edu.tr

(1st International Conference on Applied Engineering and Natural Sciences ICAENS 2021, November 1-3, 2021)

(DOI: 10.31590/ejosat.1015692)

ATIF/REFERENCE: Kapusız, B. \& Uzun, Y. (2021). Mobil Kontrol- Görüntü Aktarımı ve Lazer Savunma Gücüne Sahip Tank Robot Tasarımı. Avrupa Bilim ve Teknoloji Dergisi, (28), 1246-1253.

$\ddot{O} \mathbf{z}$

Robotlar günümüzde insan hayatını kolaylaştırmak ve insanların yapacakları hataları önceden tespit etmek amacı da dâhil olmak üzere birçok amaçla üretilmiştir. Bu makalede tasarlanan robotun (GÖKALP-01) kullanım amacı, Arduino kartının içinde bulunan ATmega mikroişlemci ile kartın içine atılan yazılım vasıtasıyla kameradan aldığı görüntü sinyallerini kullanarak mobil ve bilgisayar programlarına wifi sinyalleri ile canlı görüntü aktarımı yapmaktır. Savunma amaçlı robotun ön kısmında yer alan lazer kesim modülü ile nokta endeksli vuruş yaparak hedefi yok etmesi amaçlanmaktadır. Robotun (GÖKALP-01) üst yüzey kısmı, sensör ve aparat eklemeye uygun olarak tasarlanmıştır. GÖKALP-01, bomba imha robotu ile kullanıcının şüpheli bir nesneyi $600 \mathrm{~m}$ mesafeden inceleyebilmesini sağlamaktadır. Çelik araç platformu sayesinde ağırlık minimum seviyeye çekilerek hızlı hareket etmesini ve kayalıklı arazilerde, dik yamaçlarda, kar ve çamur gibi çevre koşullarında en zor zeminlerde rahatlık ile hareket edebilmektedir. Robotumuzun arazideki testleri yapılıp yol alması arazi şartlarına uyum sağlayıp sağlayamayacağının gerekli testleri yapılmıştır. Tanka enerji verip mobil uygulamadan kontrolü kameradan görüntü aktarılıp aktarılmadığı kontrol edilmiştir ve yapplan testlerden başarı ile geçmiştir. Tankımızın (GÖKALP-01) kullanım alanı keşif, savunma sanayi, arama kurtarmadır. Üzerine GPS modülleri gibi kartlar eklenerek girdiği arazinin konumlarını ve haritasını çıkarma gibi işlemler yapılabilir. Yapmış olduğumuz testlerde tankımızın $600 \mathrm{~m}$ alanda iletişimin kopmadığı saptanmıştır. Tankımızın üzerinde bulunan lazer modül ile 500m mesafelerde bile hedefe vurduğu ve erittiği tespit edilmiştir. Doğa ortamında yapılan bütün arazi testlerinden başarı ile çıkan tank (GÖKALP-01), rampa ortamında rampayı alırken dişlilerin bağlı olduğu paletin ön kısmından rampayı alabilmiştir.

Anahtar Kelimeler: Mikrodenetleyici, Akıllı Tank, Lazer Modül, Görüntü Aktarma, Mobil Sistemler.

\section{Mobile Control-Tank Robot Design with Image Transmission and Laser Defense Power}

\begin{abstract}
Robots have been produced for many purposes, including the purpose of making human life easier and detecting the mistakes people will make in advance. The purpose of using the robot (GÖKALP-01) designed in this article is to transfer live images to mobile and computer programs with wifi signals by using the image signals received from the camera by means of the software thrown into the card with the ATmega microprocessor inside the Arduino board. It is aimed to destroy the target by making point indexed strokes with the laser cutting module located in the front of the defensive robot. The upper surface of the robot (GÖKALP-01) is designed for adding sensors and apparatus. GÖKALP-01 enables the user to examine a suspicious object from a distance of 600 meters with the bomb disposal robot. Thanks to the steel vehicle platform, it can move quickly by minimizing the weight and can move comfortably on rocky terrains, steep slopes, and the most difficult grounds in environmental conditions such as snow and mud. Our robot has been tested in the field and the necessary tests have been made whether it can adapt to the terrain conditions or not. It was checked whether the image was transferred from the camera by energizing the tank and controlled from the mobile application and it successfully passed the tests. The usage area of our tank (GOKALP-01) is reconnaissance, defense industry, search and rescue. By adding cards such as GPS modules
\end{abstract}

*Sorumlu Yazar: burak_kapusuz_@hotmail.com 
on it, operations such as mapping the locations of the land it enters can be done. In the tests we have carried out, it has been determined that the communication of our tank is not broken in an area of $600 \mathrm{~m}$. It has been determined that with the laser module on our tank, it hits and melts the target even at 500m distances. The tank (GOKALP-01), which successfully passed all field tests in the nature environment, was able to take the ramp from the front of the pallet to which the gears were attached while taking the ramp in the ramp environment.

\section{Keywords: Microcontroller, Smart Tank, Laser Module, Image Transfer, Mobile Systems.}

\section{Giriş}

Robot olarak isimlendirilen makinelerin insanların yaşamlarını kolaylaştırmada ya da sanayide insanoğlunun yapmakta zorlandığı ya da zorlanacağı işlerde tasarlanması ve aynı zamanda üretilmesi ile ilgilenen bilim dalına ise robotik denmektedir (Ozan,2020). Üretim robotları, keşif amaçlı drone robotlar, medikal robotlar ve en önemlisi de savunma sanayi robotlarıdır. Savunma sanayi robotları, ülke güvenliğinin sağlanması açısından birçok ülkenin üzerinde özenle durduğu önemli bir konudur. Isı algılama, görüntü işleme ve takip sensörleri ile otonom hareket edilebilen robotlar bu sistemlere örnektir (Tezel,2017). Geçtiğimiz on yılda, mobil robotlar askeri ve endüstriyel ortamdan çekilerek hastaneler, okullar ve sıradan evler gibi sivil ve kişisel alanlara girmektedir. Robotlar, özellikle tekrar eden görevleri yerine getirmede insanların yerini almaktadır. Robotik genel olarak, endüstriyel ve servis robotları olmak üzere iki alana ayrılabilir. Uluslararası Robotik Federasyonu hizmet robotunu, insanların refahı için faydalı olan hizmetleri gerçekleştiren, kısmen veya tamamen bağımsız olarak çalışan bir robot olarak tanımlamaktadır (Karacı ve Erdemir,2017).

Yapılacak işin farklı yerlerde gerçekleştirilmesi robotların gezgin olmasını gerektirmektedir. Bu tür görevlere yönelik olarak tasarlanmış gezgin robotlar üç kısımdan oluşur. İlk kısım hareketi sağlayan mekanik, ikinci kısım kontrol birimleri ve algılayıcılar vasıtasıyla algılanan verilerin işlenmesini sağlayan donanım, üçüncü kısım ise hareket kontrolünü ve karar almayı sağlayan yazılımdır (Özdemir ve Köse,2008). Arduino; birçok kişi tarafindan yaygın olarak kullanılan bir mikro denetleyici karttır. Esnek, kullanımı kolay ve eksiksiz bir donanım ve yazılım ortamı sunar. C / C ++ temelli Arduino dili kullanılarak programlanabilmektedir. Ayrıca Arduino'nun Windows, OS X ve Linux sistemleri için entegre geliştirme ortamı (IDE) mevcuttur ve bu ortamda çok sayıda öğretici ve kapsamlı belge bulunmaktadır (Karacı ve Erdemir,2017).

.Elektronik devrelerde mikrodenetleyiciler, kontrolcü, veri akışı sağlama ve denetleme görevlerine sahip yaygın olarak kullanılan devre elemanlarıdır. Bünyelerinde zamanlayıcı, sayıcı, giriş çıkış portları, analog sayısal çevirme ünitesi, RAM bellek, ROM bellek, PWM darbe üreteci, seri haberleşme birimi, ALU ve benzeri birimler bulundururlar (Bay ve Görgünoğlu,2002). Arduino, processing /Wiring dilini kullanarak çevre elemanları ile temel çıkış uygulamalarını gerçekleştiren açık kaynaklı fiziksel programlama platformudur (Güngör,2015). Arduino kart ucuzdur ve ihtiyaca uygun olarak satın alınan shield denilen çevre birimleri vasıtasıyla genişletilebilir. Arduino çok ucuz ve kolay erişilebilir bir kart olmasına karşın çok işlevseldir. (Karacı ve Erdemir,2017).

$\mathrm{Bu}$ makalede tasarlanan robot (GÖKALP-01), yukarıda belirtilmiş olan bilgiler doğrultusunda gerçekleştirilmiştir. Robotun kullanım amacı, Arduino kartının içinde bulunan
ATmega mikroişlemci ile kartın içine atılan yazılım vasıtasıyla kameradan aldığı görüntü sinyallerini kullanarak mobil ve bilgisayar programlarına Wifi sinyalleri ile canlı görüntü aktarımı yapmaktır. Savunma amaçlı robotun ön kısmında yer alan lazer kesim modülü ile nokta endeksli vuruş yaparak hedefi yok etmesi amaçlanmaktadır.

Tasarlanan robotun amacı dikkate alınarak makale özelinde araştırmanın problem cümlesi, "Savunma sanayisinde kullanılmak üzere tank robot tasarımı nasıl yapılabilir?" olarak belirlenmiştir. Tank robotumuzun (GÖKALP-01) kasasının üst bölümü, sensörler ve elektronik devre elemanlarını konumlandırmak amacı ile eğimli ve montaj delikleri hazır bir şekilde elde edilmiştir. Tank robotta, $12 \mathrm{~V}$ redüktörlü DC motor 2 adet kullanılarak Solidworks'te kasa tasarımı yapılmıştır. Paletlere, gövdeye uygun bir şekilde montaj edilebilmesi için kasa 4 kısımda birleşebilecek şekilde oluşturulmuştur, Arduino kartta, Wifi modem kart yardımı ile Android cihazlardan gönderilen sinyalleri motorlara aktararak motorların harekete geçmesi sağlanmaktadır. Dişlilerde ve rulmanlı tekerlerde oluşan DC motorların hareketi paletlere aktarılmakta ve tankımızın (GÖKALP-01) harekete geçmesi sağlanmaktadır.

\section{Materyal ve Metot}

Makalenin konusunu oluşturan tank yapımı 4 aşamadan geçilerek oluşturulmuştur. Bu aşamalar, makine kısmı, elektronik montaj, Enerji kaynağının oluşturulması ve mobil uygulama tasarımıdır. İlk olarak Solidworks programı kullanılarak tank kasasının tasarımı yapılmıştır. Yapılan kasa tasarımı 4 aşamada birleştirilmek amaçlı yapılmış ve çeliğe krom katılarak sactan oluşturulmuştur. Oluşturulan çelik sac kasa ağır hava şartları altında paslanmaya karşı dayanıklıdır. Şekil 1'de kasa tasarımı gösterilmiştir.

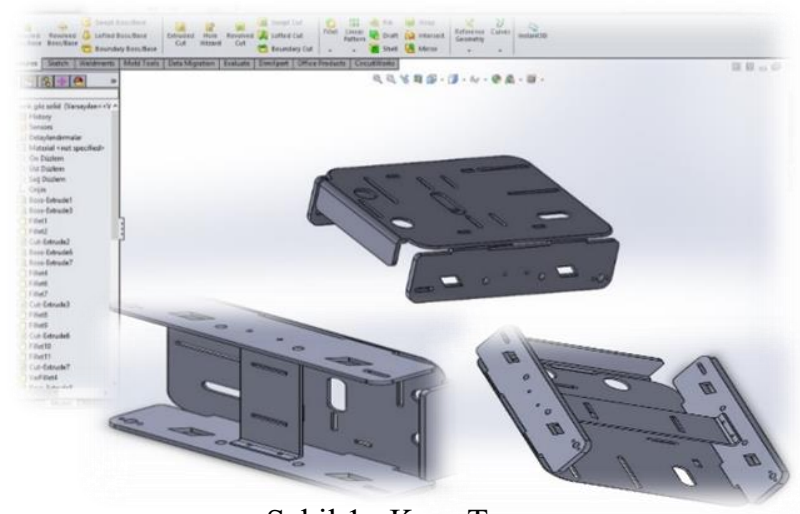

Şekil 1 Kasa Tasarımı

Bir DC motorun gerçek zamanlı hız denetimi birçok alanda istenen bir fonksiyondur. Günlük hayatta karşımıza çıktığı gibi endüstride yüksek güç gerektiren birçok alanda kullanılmaktadır (Postalcıŏlu ve Köktürk,2019). Paletleri döndürebilmek için 12V DC Redüktörlü motorlar kullanılmış, de motorlarımızın hız ayarlamaları yazılımla sağlanmıştır mobil uygulamadan sağ ve sol motorların hız ayarı yapılabilmektedir ve kasaya montaj edebilmek için matkapla çelik sacda delikler açılmıştır. Bu şekilde 
motorlar kasaya sabitlenmiştir. Kasanın üst kısmında yer alan saca elektronik devre kartlarını montaj edebilmek için CNC frezede alanlar açılmıştır. Paletler kauçuk plastik malzemeden yapılmıştır ve paletlerin yere daha iyi tutunabilmesi amaçlanmıştır.

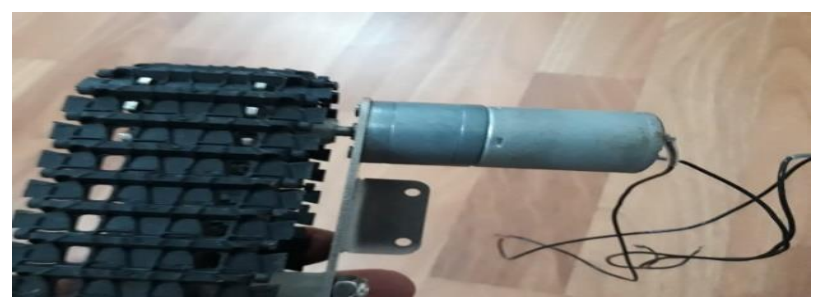

Şekil 2 12V Redüktörlü Motor Montajı

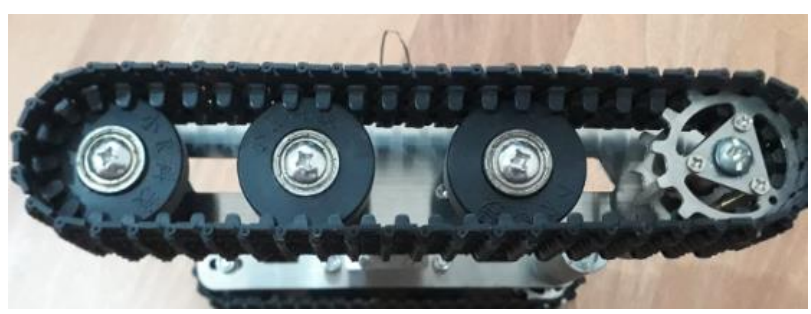

Şekil 3 Palet Tasarımı

Makine kısmına geçildiğinde ilk olarak robotun (GÖKALP01) ana kasa hatları tasarlanmıştır. Daha sonra mekanik hareket verebilmek amacıyla çizimleri yapılmış ve montajı sağlanmıştır. Tank motorunun, motor mil ölçüsü alınıp tasarlanan dişli aralığına tam bir şekilde oturup oturmadığ 1 test edilmiştir. Çizmiş olduğumuz CAD resimlerinin karşılarına oklar çıkararak belirtilen kısımlara montajı yapılacak motorların teker teker açıklamaları yapılmıştır. Montaj işleminde kısımların, motorların hangi noktalarına bağlanacağı belirtilmiştir. Teknik resim kurallarına uygun olarak çizilen parçaların renkli ve teker teker gösterimi sağlanmıştır. Belirtilen kurallara uygun montaj aşamalarını anlatılmıştır.

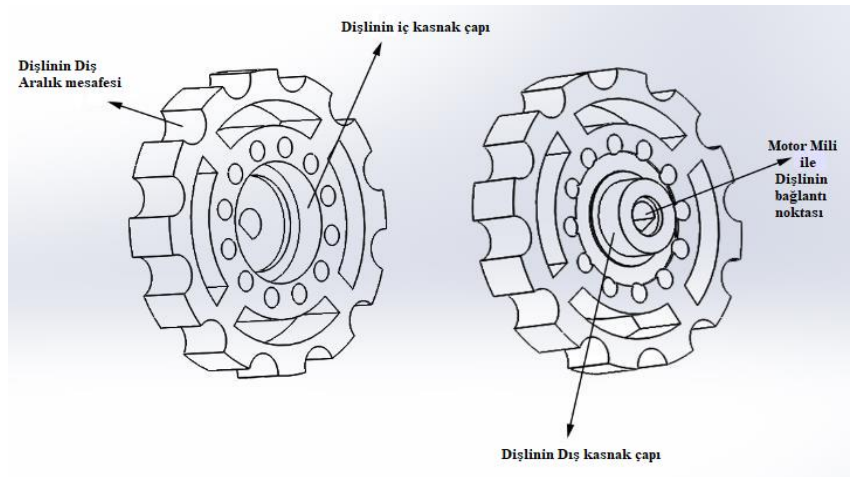

Şekil 4 Motor ve Paleti Birleştiren Dişli Tasarımı

Palet ve kasa birleşim aşamalarında tasarlanmış ve tasarıma göre üretilmiştir. DC motorların arka kısmında yer alan terminallere kablolar lehimlenmiştir. Lehimlenen kablolara ilerleyen aşamalarda ARDUINO kartın üstünde yer alan motor sürücü kartına bağlantıları yapılmak için bırakılmıştır. Elektronik kısma geçilmeden önce günümüzde kullanılan tanklardaki dişli problemlerine dikkat edilmelidir. Günümüzdeki tanklarda palet hareketleri birbiri içine yataklanmış birçok dişlinin birbirini döndürmesi ile sağlanmaktadır. Ana dişli motora bağlanmakta ve paletin her noktasına hareket, dişlilerin birbiri içine geçmiş hareketi sayesinde aktarılmaktadır.
$\mathrm{Bu}$ yüzden de dişliler birbirlerine sürtünerek aşınmalara sebebiyet vererek ilerleyen dönemlerde paletlerin tanktan çıkmasına neden olmaktadır. Bu durumlarda tasarım yapılırken dişlilerde, basınç ve motor kuvvetlerini daha küçük veya büyük ebatlardaki dişlilere aktarılması yönündeki gayret, büyük ebatlardaki dişlilerde sorun oluşturmazken küçük ebatlardaki dişlilerde, birim alana düşen yük miktarını arttırmaktadır. Bu tip dişlilere, "ağır yük dişlisi" denilmektedir. Düz ve helis tip dişlilerin küçük ebatlarındaki dişliler, günümüzde savunma sanayisinin yanı sıra otomotiv sanayisinde de çok fazla miktarda kullanılmaktadır. Ağır yük dişlisinde oluşan aşırı yükten ötürü hareketinde gürültü ve titreşim olmaktadır.

Günümüzde tankların ve savunma sanayisinde kullanılan diğer araçların hareketlerinde gürültü ve titreşim oluşmasına sebep olan dişliler çözülmesi gereken bir sorun olarak karşımıza çıkmaktadırlar. Tank, gemi gibi büyük kuvvetleri hareketlerinde gürültü ve titreşim sorunu özellikle askeri hareketlerde ve uygulamalarda büyük öneme neden olmaktadır. Günümüzdeki tankların dişli problemi de göz önünde bulundurularak titreşim ve gürültüyü azaltmak amaçlı tank paletlerinin hareketlerini rulmanlı tekerler kullanılarak hareket paletin diğer kısımlarına dağılmaktadır. Dişli sistem olarak motorun palete bağlandığı yer kullanılmış ve dişlinin paletin içine geçerek döndürme hareketini sağlanması istenmiştir. Tankın elektrik kısmında enerjiyi sağlayan pil tasarımında atık laptop bataryaları tercih edilmiştir. Laptopların bataryalarında bulunan LIPO (lityum-polimer) piller ile batarya tasarımı sağlanmıştır. Bunun içinde pil voltaj değerlerinin ölçümü Avometre ile yapılmıştır.

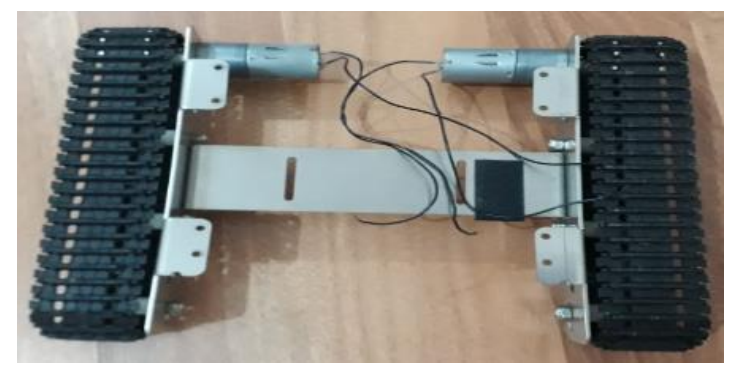

Şekil 5 Palet Tank Montaj1

Telefon, tablet, bilgisayar, insansız hava aracı gibi yaşamımızın birçok alanında kullandığımız cihazlarda enerji depolamak ve bu enerjiden faydalanmak için lityum temelli (lityum-iyon, lityum-polimer ve benzeri) piller kullanılmaktadır. $\mathrm{Bu}$ pillerin kendi yapılarına, özelliklerine ve ihtiyaçlarına göre şarj edilerek yapılan işlemlerin belli bir standart ve uygunlukta olması gerekmektedir (Gelen ve Tüfekcioğlu,2020).

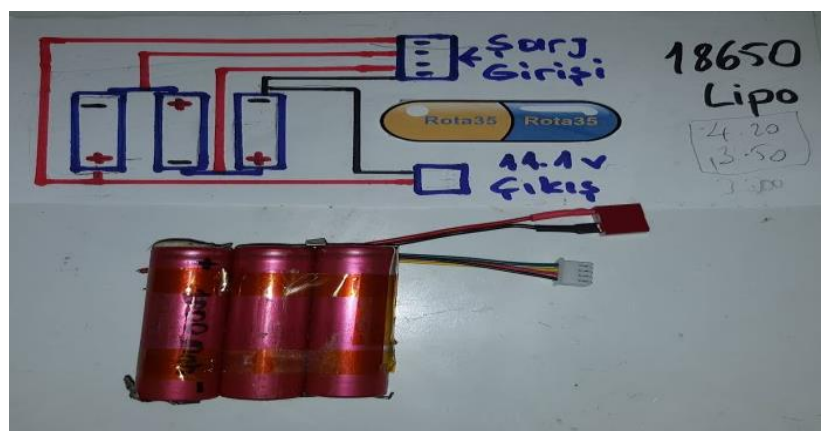

Şekil 6 Pil Montaj1 
$\mathrm{Bu}$ standartlar sağlandığı zaman pillerden alınan verim ve kullanım süreleri artmaktadır (Gelen ve Tüfekcioğlu,2020). Piller ölçüldüğünde elde edilen voltaj $3.7 \mathrm{~V}$ civarındadır. Bu da pillerin boş olduğunu göstermektedir. Dolu LİPO pilin $4.2 \mathrm{~V}$ enerjiye sahip olduğunu bilinmektedir. Tankı çalıştırmak için gerekli olan voltaj $12 \mathrm{~V}$ civarındadır. Bunun için de bataryadan çıkarılan 3 tane pil birbirine seri olarak bağlanarak devre tasarımı tamamlanmıştır. Böylece $12 \mathrm{~V}$ enerji kaynağını elde edilmiştir. Bu tip piller için özel şarj aletleri bulunmakla birlikte elimizde bulunan İMAX B6 şarj aleti ile piller şarja bırakılmıştır. Kullanılan atık pillerin üst kısmında + ve - kutupları gösterilmektedir. Seri bağlantı için pilden alınan + kutup diğer pilin - kutbuna bağlanmalıdır. Pilin dış kısmına ısı ile daralan PVC Shrink makaron plastik eklenmiş tanka montajı için tankın alt kasasına ve pilin üstüne cırt cırt eklenmiş̧ir.

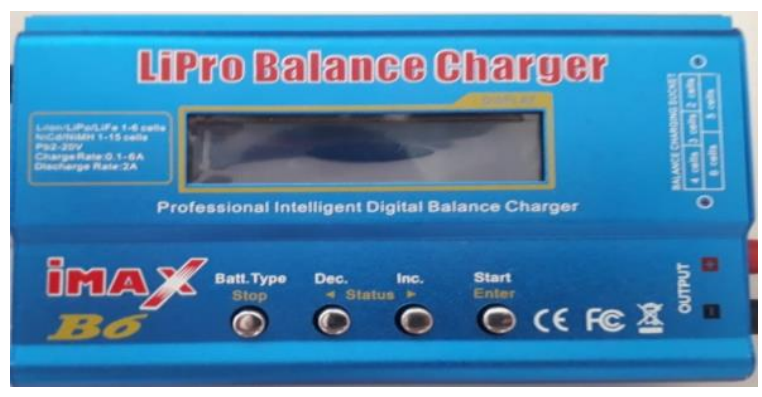

Şekil 7 LİPO Pil Şarj İstasyonu

Tankın (GÖKALP-01) elektrik kaynağını oluşturan LIPO pillerin nasıl yapıldığı anlatıldıktan sonra elektronik bağlantıların, kullanılacak elektronik devre elemanlarının tanıtımı ve bağlantılarının nasıl yapılacağı ele alınacaktır. Elektronik bağlantılarda Fritzing programından yararlanılmıştır. Fritzing programı aynı zamanda simülasyon yapma özelliğine de sahip olduğu için Arduino kartın içine atılan yazılımın da elektronik elemanların çalışmasının da testine imkân tanımaktadır.

Kullanılan elektronik devre elemanları, Arduino Uno, Motor Shield kart, 5500 MW Cnc Lazer modül, Wifi modem kart, 2 adet kameranın 180 derece açı ile yukarı-aşağı, sağa-sola hareket edebilmesi için servo motor, web camera ve motorların hareketini sağlamak ve elektronik devre kartların beslemek için $12 \mathrm{~V}$ Lityum polimer batarya ve tankın harekete geçmesini sağlayan 12V Redüktörlü DC motorlardır. Tankın (GÖKALP-01) elektronik kısmını oluşturan bütün devre elemanları teker teker incelenmiş ve kullanmadan önce içlerine atılan driver ve yazılımlar hakkında bilgi verilmiştir.

Ardunio Uno, dijital ve analog girişlere ve çıkışlara sahip bir kart olmakla beraber processing /Wiring temelli hazır kütüphanelere sahip geliştirme ortamı olan bir platformdur. Ardunio kart, yapisinda bulunan Atmega328 model entegreli bir işlemciye sahiptir. Kolay bir şekilde bilgisayara USB kablosu ile bağlanarak seri haberleşme sağlayarak bilgisayar ile programlanabilmekte ve seri veri haberleşmesi sağlayabilmektedir.

Ardunio Uno kart tasarlanan tankta (GÖKALP-01) kullanılan mikroişlemci karttır. Wifi modül kartın üstünde dönüştürücüler bulunmaktadır. Bu dönüştürücü sayesinde USB portu üzerinden sanal bir COM port oluşmakta ve modül ile doğrudan seri iletişime geçebilmektedir. Web Kamera USB portta seri porttan bağlanıp sanal comdan veri göndermesine izin verilmiştir. Firmware yükleme, komut gönderimi, hata ayıklama vesaire ihtiyaç olan ne varsa bu tip bir dönüştürücü sayesinde kolayca yapılabilmektedir. $\mathrm{Bu}$ bir opsiyon olmamakla birlikte bir dönüştürücü almak zorunluluktur. Dönüştürücüye ilişkin Driver bilgisayara kurulduktan sonra Windows/Denetim Masası/Aygıt Yönetici ’sinden \$ dmesg / grep tty gibi bir komutla seri portlar listelenmekte ve ilgili dönüştürücüyle ilişkili olanın bulunması gerekmektedir.

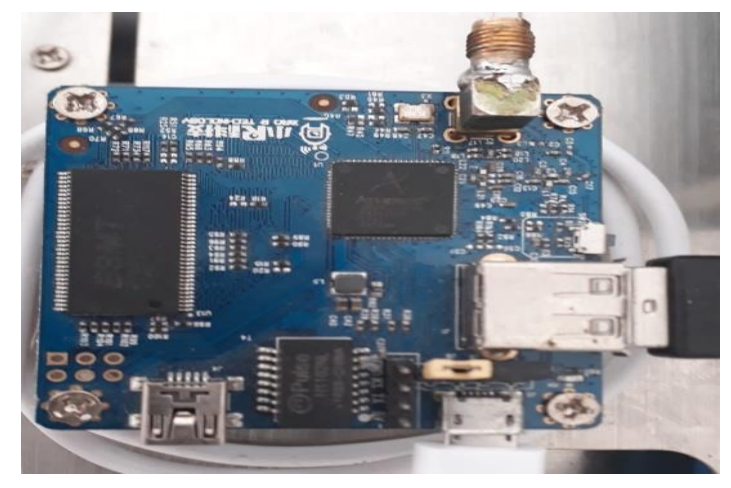

Şekil 7 Wifi Modem Kart

Bu port ismi (örneğin, Windows için COM8) daha sonra firmware yükleme işlemi için kullanılacaktır. Bir hatırlatma yapılması gerekirse, modülünüzün zarar görmemesi için dönüştürücüyü, üzerinde bulunan jumper vasitasıyla $3.3 \mathrm{~V}$ güç modunda kullanılmalıdır. Firmware yüklemesi yapıldıktan sonra Wifi modül karta enerji verebilmek ve seri haberleşme yapıp veri aktarabilmek için motor sürücü kartın üstünde bulunan USB porttan Wifi modem karta kablo yardımı ile bağlanmaktadır. Modem kartın sinyalini artırmak için anten takılabilmektedir. Tanka montaj sırasında kart zarar görmesin diye yükseklik verilerek montajı sağlanmıştır.

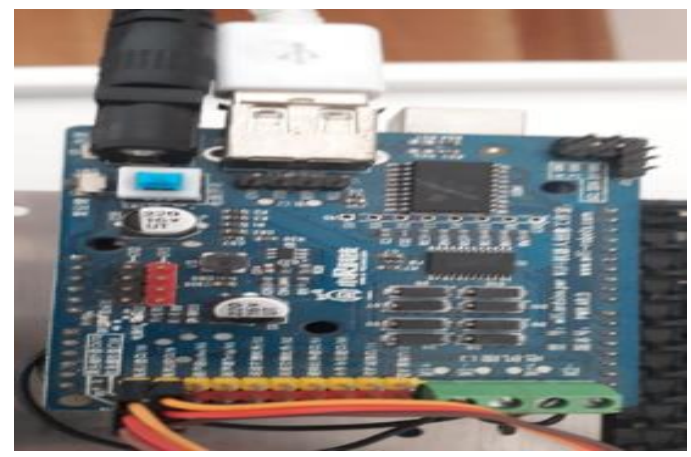

Şekil 8 Motor Shield Kart

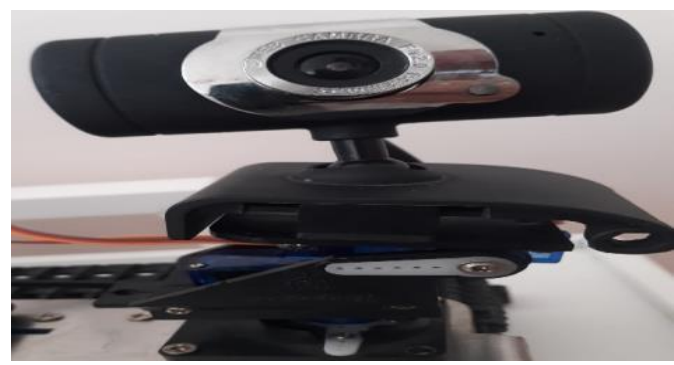

Şekil 9 Servo Motorlu Kamera

Motor Sürücü kartı ile 2 adet servo ve 2 adet DC motor sürebilmek için üstünde bağlantı noktaları bulunmaktadır. 
Kaynak yazılım yapıldıktan sonra telefondan kontrol edilebilmek için motor sürücü bağlantı yerleri yapılmıştır. Bu kart aynı zamanda Wifi modülün ağ kurup Android cihazlarla iletişim kurabilmesi için Wifi modem kartı çalıştırmaktadır. Servo motorlar hız ve ivme kontrollerini hatasız bir şekilde yapan belirli açılara sahip ve gönderilen açılarda sabit olarak açısal ve doğrusal pozisyon ayarlarını yapabilen mekanizmalara sahip motorlardır. Servo motorlar robot teknolojilerinde çok kullanılan motorlar olmakla birlikte yapılan açısal hareketleri her geçen gün geliştirilmektedir. RC arabalarda sağa ve sola doğru yönelmelerde kullanılmaktadır.

Servo motorlar büyük güç, yüksek moment ve hızlı tepki gerektiren sistemlerde daha çok kullanılmaktadır (Yılmaz,2008). Servo motorların en çok tercih edilme sebebi gelen komutu yerine getirdikten sonra orada sabit olarak kalabilmesidir. Açısal kontrolü bulunduğu için ve bulunduğu konumda kalabilme özelliğinden kameramızın hareketlerinde Servo motorlar kullanılmıştır. Genellikle çalışma açıları 180 derece ile sınırlıdır. Özel amaçlı olarak 360 derece açıda çalışan Servolarda kullanılmaktadır. Kullanılan sistemde 180 derece açı yapabilen Servolar tercih edilmiştir.

\subsection{Fritzing Programında Tasarlanan Devre Şeması}

\subsubsection{Devrede Kullanulan Elemanlar}

Motor Shield ile Arduino UNO birbirine paralel bir şekilde bağlanmıştır. GÖKALP-01 bomba imha robotu ile kullanıcının şüpheli bir nesneyi $600 \mathrm{~m}$ mesafeden inceleyebilmesini sağlamaktadır. Çelik araç platformu sayesinde ağırlık minimum seviyeye çekilerek hızlı hareket etmesini ve kayalıklı arazilerde, dik yamaçlarda, kar ve çamur gibi çevre koşullarında en zor zeminlerde rahatlık ile hareket edebilmektedir.

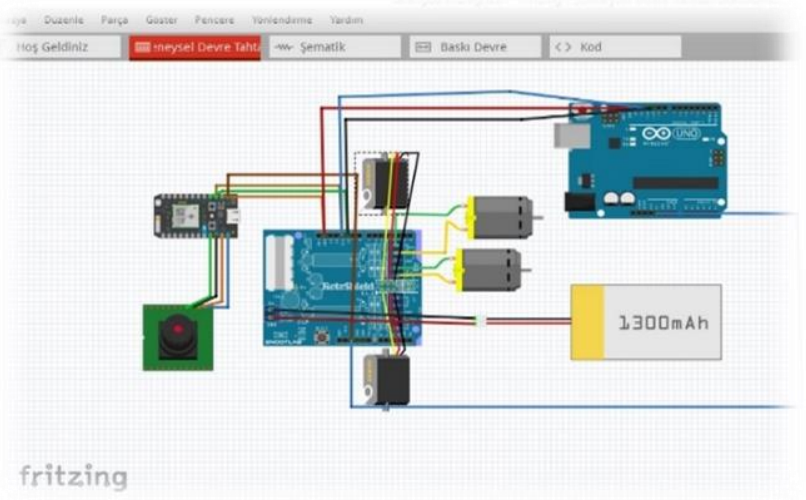

Şekil 9 Devre Elemanları

İnsanların gözünde bomba imha robotu denildiği zaman genellikle ağır, sabit kameralı, yavaş hareket eden, akü ile beslenen, robot kol ile tehlikeli nesnelere müdahale eden mini tanklar gelmektedir. Tasarlanan tankta (GÖKALP-01) ise robot kol olmadığ lazer ile yakılarak imha edilmekte, kameramız $180^{\circ}$ aşağı- yukarı, sağa-sola hareket edebilmekte ve hedefi her açıdan görebilmeyi sağlamaktadır.

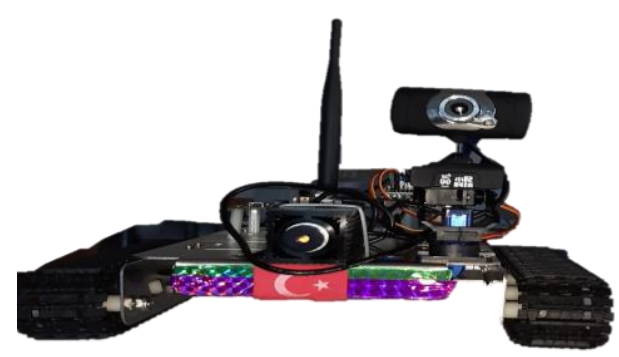

Şekil 10 GÖKALP-01 Tank Robot

$12 \mathrm{~V}$ enerji, LİPO pillerden sağlandığı için hareket hızı yükselmekte ve kasa çelik sactan yapıldı̆̆ 1 için ağırlık $3 \mathrm{~kg}$ geçmemektedir. Bomba imha uzmanlarına ve askeri alanlarda hızı yükseltilmiş ağırlığı düşürülmüş, her açıdan görme imkânı sağlayan imha robotu çok yararlı bir şekilde kullanıma hazırlanmıştır.

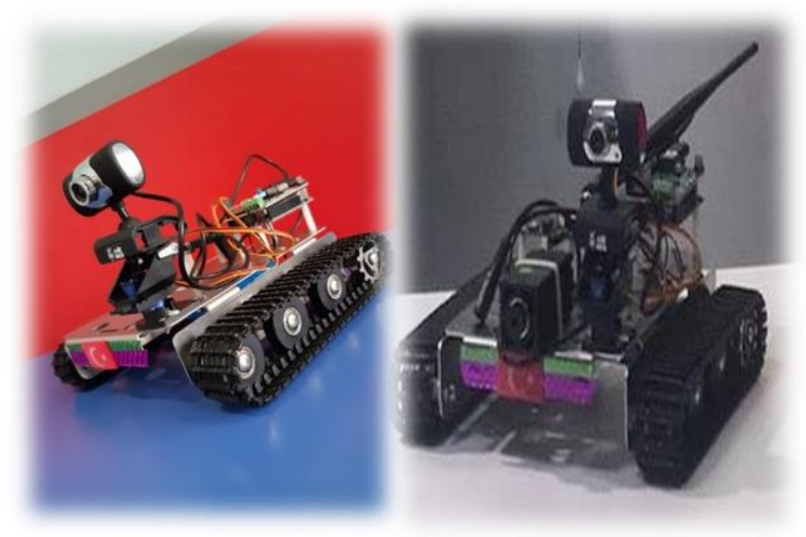

Şekil 11 GÖKALP-01 Tank Robot

Mobil uygulama tasarımında Mit App Inventor uygulaması kullanılmıştır. Mobil uygulamada ilk aşamada kameradan telefona veriler aktarılabilmesi için her komuta belirli adresler verilmiştir. Mobil uygulamanın belirli aşamaları hakkında bilgi verilmiştir. Arduino Kartın içine yüklenen yazılım ve ayrıntılı mobil uygulama kod blokları hakkında bilgi verilememiştir. Makale sayfa sayısının yükselmemesi için belirli komutlar açıklanmıştır.

\subsubsection{Arduino Programında Verilen Komut Adresleri}

SOLA $=$ FF000300FF

İLERİ SOLA= FF000700FF

GERİ SOLA $=$ FF000700FF

SOLA DÖN $=$ FF000700FF

SAĞA $=$ FF000400FF

İLERİ SAĞA= FF000600FF

GERİ SAĞA = FF000800FF

SAĞA DÖN = FF001000FF

$\mathrm{DUR}=\mathrm{FF} 000000 \mathrm{FF}$

PORT ADRESİ=2001

IP ADRESİ=192.168.1.1 

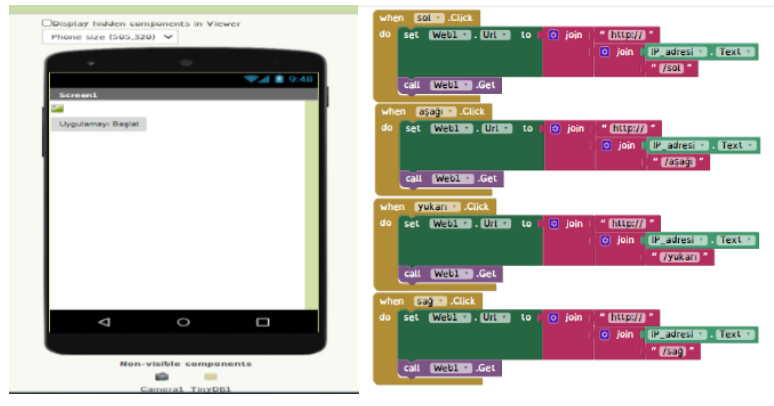

Şekil 12 Mit App İnvertor Programı ile Kameranın Görüntü Aktarım Kısmı

Mobil uygulamaya kamera komutunun aktarılabilmesi için Mit App İnvertor programı içerisinden bir buton seçilmekte ve uygulamayı başlat sekmesi işlenmektedir. Bu butona basıldığında kamera başlasın sekmesi verilmekte ve yazılan yazılım ile kameranın açılacağı görüntü aktarımının başlayacağı sayfa açılmaktadır.

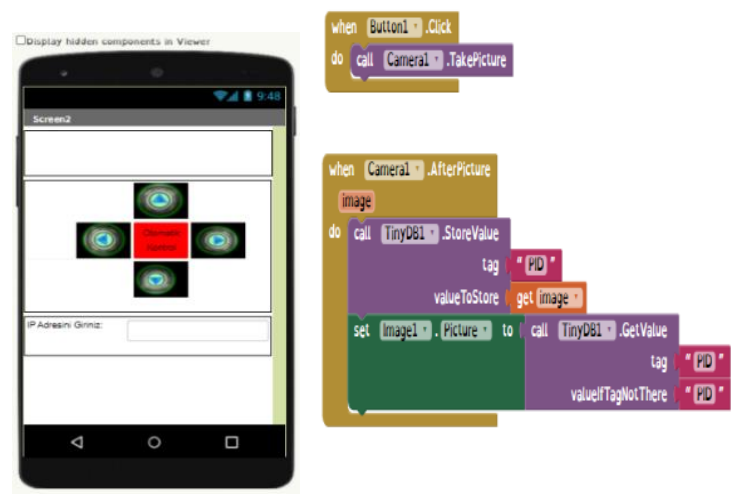

Şekil 13 Mit App Invertor Programı ile Telefondan Kontrol Komutları

Yukarıda verilen sayfada 4 adet buton tanımlanmıştır. Tankı mobil uygulamadan kontrol etmek için sağa ve sola geri durdurma komutları için tanımlamalar yapılmıştır. IP adresi girildiği zaman Wifi modem kartına ulaşılmakta ve gerekli komutlar tankın kontrolü uzaktan yapılabilir konuma gelmektedir.

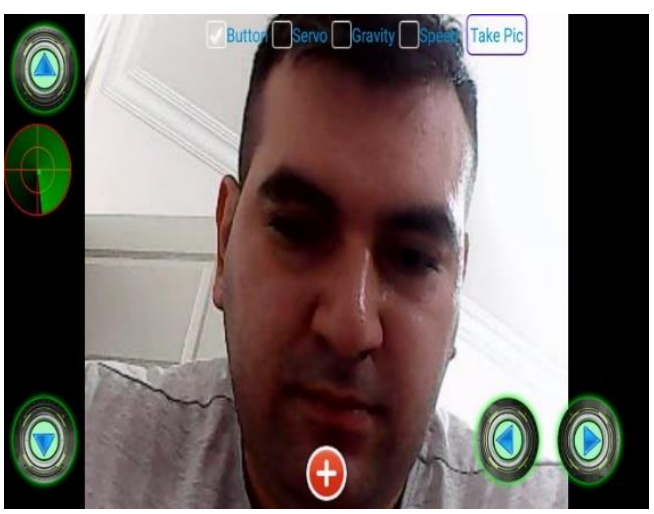

Şekil 14 Görüntü Aktarma Testi

\section{Araştırma Sonuçları ve Tartışma}

Bulgular kısmında tank robotumuza yapılan testler ile ilgili bilgiler verilmiştir. İlk olarak tank robotumuzun enerji kaynağı olan 12V LIPO piller Avometre ile ölçülerek enerjideki veya pillerde bir sıkıntı olup olmadığı tespit edilmiştir. Daha sonra motorlarımızın ve elektronik diğer elemanlarımızın kaç amperlik akım çektiği tespit edilmiştir. Böylelikle enerji kaynağımızın kaç saatlik kontrol sağlayacağı tespit edilmiştir burada yapılan hesaplamalarda enerji kaynağımız sorunsuz bir şekilde 3.5 saatte kadar tankı çalıştırabilmektedir.

Tankın (GÖKAL-01 belirli engebeli arazilerde, doğa ortamında ve rampalarda nasıl hareket ettiği zorlu yollarda engelleri aşıp aşamaması üzerine testler yapılmıştır. Elektriksel olarak testlerde uygulandı ve özellikle rampaları alırken motorlara aşırı yük binmesi üzerine motorların çektikleri akımlar yükseldi bunların ayrıntılı hesaplamaları yapılmıştır. Robotumuza yapılan testler uluslararası robot testleri ile aynı statülerdedir.

Robotumuzun arazideki testleri yapılıp yol alması arazi şartlarına uyum sağlayıp sağlayamayacağının gerekli testleri yapılmıştır. Tanka enerji verip mobil uygulamadan kontrolü kameradan görüntü aktarılıp aktarılmadığ 1 kontrol edilmiştir ve yapılan testlerden başarı ile geçmiştir. Mobil uygulamadan tankın hareketlerini sağlayan DC motorların kontrollerini, etrafında olan nesneleri algılamak için radar sistemini, kamerayı hareket ettirebilmek için Servo motor kontrollerini, yerçekimini, DC motorların hız ayarlarını ve kameranın çektiği görüntüleri cihazımıza kayıt ettirme gibi birçok özelliği sağlamaktadır.
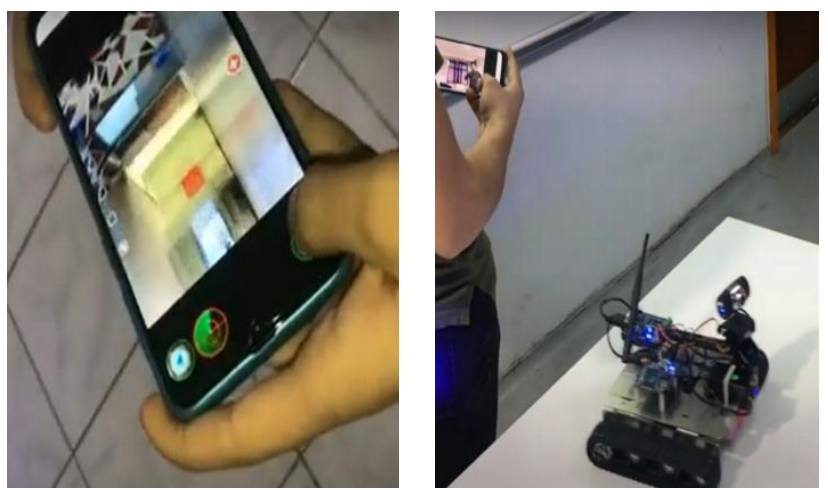

Şekil 15 Mobil Uygulama Hareket Testi

Lazer modülün mesafe testi yapılmıştır. Ne kadarlık mesafede hedefe zarar verdiği tespit edilmiş, $500 \mathrm{~m}$ yarıçapa sahip alana kadar hedefi erittiği tespit edilmiștir. Bu test, insan veya bir hayvan üzerinde tespit edilmemiştir. Duvara bıraktığı yakma izleri üzerinden tespit yapılmıştır. Ayrıca GÖKALP-01'in Çakıl Taşı Testi, Kum Testi ve Rampa Testi de yapılmış olup, testler başarılı sonuçlanmıştır.
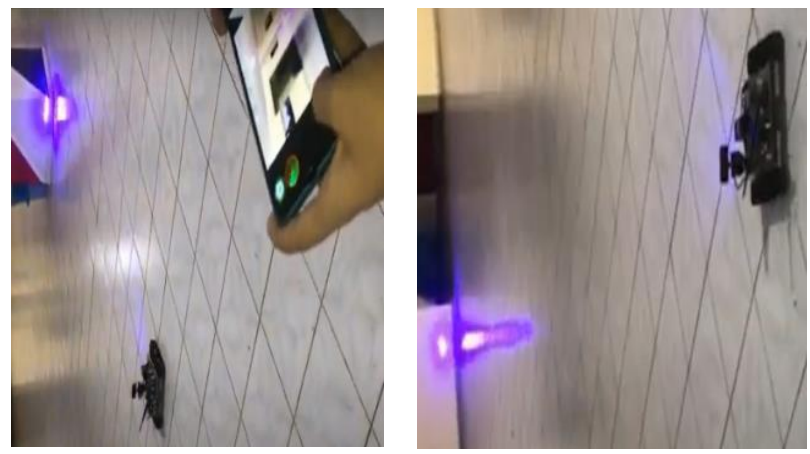

Şekil 16 Lazer Modül Mesafe Testi 


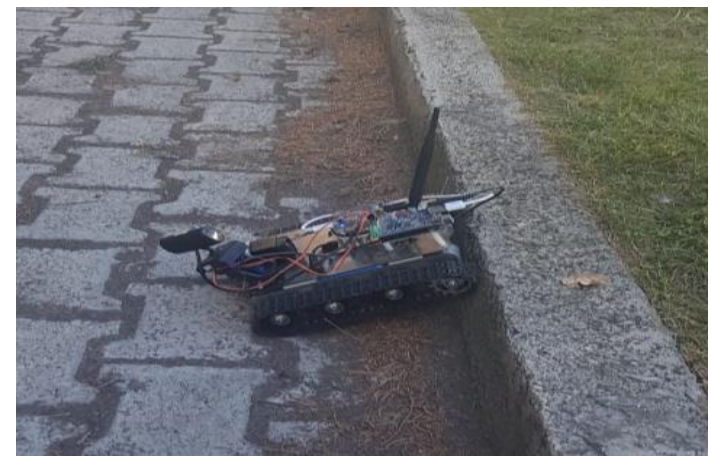

Şekil 17 Rampa Testi

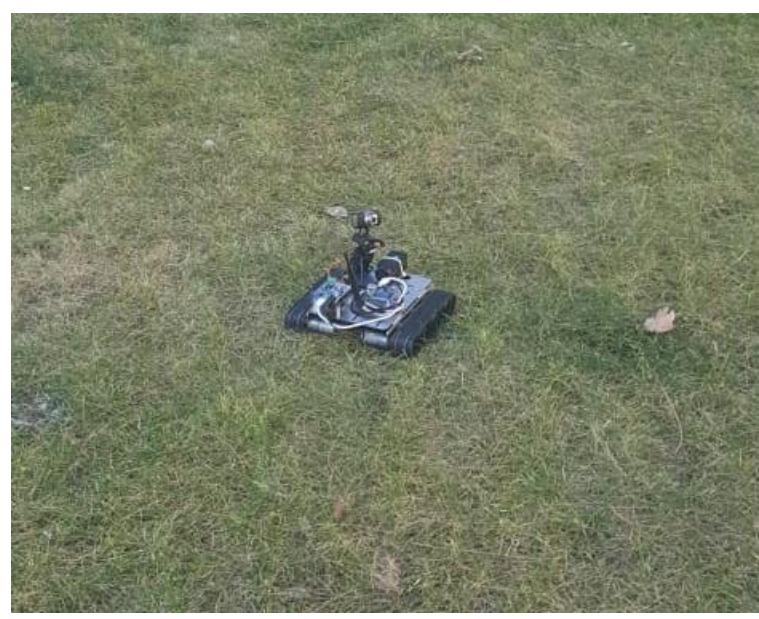

Şekil 18 Çim Testi

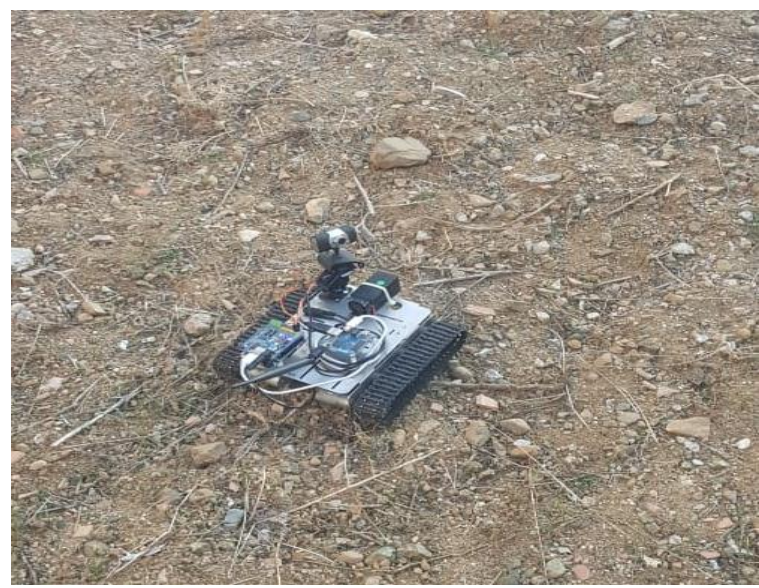

Şekil 19 Çakıl Taşı Testi

Tasarlanan tank robotta (GÖKALP-01) hazır kütüphaneleri olması sebebiyle Arduino tercih edilmiştir. Arduino kartta işlemcinin verileri işleme hızı, yani telefondan mobil uygulama ile gönderilen sinyalleri tankın hareket mekanizmasına geçirmesi 1s kayıplara neden olmaktadır. Bunun ile ilgili olarak da Arduino kullanılan mikroişlemci kartta iyileştirmeler yapılarak kart tekrar programlanmış ve içerisinde bulunan mikroişlemcide ki seri ekran haberleşme hızını 9600'den 115200 çıkardık kartın hızlı veri işlemesi sağlanmıştır.

Bunun dışında Wifi modem kartında da iyileştirilmeler yapılmış, kullanılan anten ve kartın bağlantı noktasına lehimleme işlemleri yapılmış ve uzaklık mesafesinde $50 \mathrm{~m}$ bir alan daha kazanmış olduk. Tankımızda (GÖKALP-01) bulunan Arduino kart çekmiş olduğu akımın düşüklüğü, ebatları ve vida montajı için üzerinde bırakılmış olan delikler sayesinde kullanım sebebi olmuştur. Tasarımda tankın (GÖKALP-01) üst kısmına kartları montaj edebilmek için bırakılan deliklere Arduino üzerinde bulunan delikler tam olarak oturmuştur. Böylelikle rahat montaj sağlamıştır.

Tankın kasası çelik sac olduğu için tankta kullanılan elektronik kartların bu zemine oturduğunda kısa devre yapma sıkıntısı oluşturabileceği için gerekli yükseltmeler yapılmış ve elektronik kartların kasaya teması kesilmiştir. Arduino kartın internet ortamında açık kaynak yazılımına sahip bir kart olduğu için birçok örnek yazılım bulunmaktadır. Herhangi bir problemde internet ortamından yararlanılarak yazılımda gerekli düzeltmeler yapılabilmektedir.

\section{Sonuç}

Tankımızın (GÖKALP-01) kullanım alanı keşif, savunma sanayi, arama kurtarmadır. Üzerine GPS modülleri gibi kartlar eklenerek girdiği arazinin konumlarını ve haritasını çıkarma gibi işlemler yapılabilir. Buna ek olarak, tankın üzerinde bulunan kameradan yararlanarak çektiği görüntüleri aktarması sayesinde o konuma giden insanlar arazinin şartları hakkında bilgi sahibi olabilmektedir. Bu sayede keşif ve arama kurtarma gibi görevlerin üstesinden başarı ile gelebilmektedir. Kameranın bağlı olduğu Servo motorların hareketleri sonucunda görüş açısında yüksek oranda düzelme olmuş ve stabil bir kamera yerine hareketli kamera sayesinde görüş açımızın artırılması sağlanmıştır.

Bunun dışında güvenlik ve arazi şartları ile doğru orantılı çalışabilecek bir tank elde edilmiştir. Krom katılarak oluş̧urulan çelik sac sayesinde tank (GÖKALP-01) hafiflik kazanmış ve hava şartlarına karşı yüksek dayanıklılık göstermesi sağlanmıştır. Tankta (GÖKALP-01) kullanılan 12v DC redüktörlü motorlar sayesinde manevra ve hız kabiliyeti artmıştır. Haberleşme sisteminde kullanılan Wifi modem kartı sayesinde yüksek mesafelerden bile kontrolü sağlanmış, veri akış hızı artırılmıştır. Yapmış olduğumuz testlerde tankımızın $600 \mathrm{~m}$ alanda iletişimin kopmadığı saptanmıştır. Tankımızın üzerinde bulunan lazer modül ile $500 \mathrm{~m}$ mesafelerde bile hedefe vurduğu ve erittiği tespit edilmiştir. Doğa ortamında yapılan bütün arazi testlerinden başarı ile çıkan tank (GÖKALP-01), rampa ortamında rampayı alırken dişlilerin bağlı olduğu paletin ön kısmından rampayı alabilmiştir. Tam tersi yöndeki denemelerde tankımız zorlanmıştır. Motordaki kuvvet aktarıldığı için ön kısmındaki torku ile palete bağlandığımız rulmanlı tekerin olduğu arka kısmındaki torklar arasında farklılıklar vardır.

\section{Teșekkür}

$\mathrm{Bu}$ çalışmanın gerçekleştirilmesinde kıymetli bilgilerini paylaşan saygıdeğer danışman hocam Dr. Öğr. Üyesi Yusuf Uzun'a ve çalışmam boyunca benden bir an olsun yardımlarını esirgemeyen, çalışma süresince tüm zorlukları benimle göğüsleyen ve hayatımın her evresinde bana destek olan değerli eşim Bilgehan IYYIGÖREN KAPUSIZ'a sonsuz teşekkürlerimi sunarım.

\section{Kaynakça}

Bay, Ö. F. ve Görgünoğlu, S. (2002). 8051 Ailesi Mikrodenetleyici Eğitim Setinin Tasarımı ve Gerçekleştirilmesi, Politeknik Dergisi, 5 (3), 195-207. 
Gelen, A. ve Tüfekcioğlu, E. (2020). Lityum- Polimer Piller İçin Şarj ve Dengeleyici Devre Tasarımı, Erzincan Üniversitesi Fen Bilimleri Enstitüsü Dergisi, 13(2), 839-846.

Güngör, O. (2015). Kaçak Elektrik Kullanımının GSM Aracılığıyla Takibi, EMO Bilimsel Dergi, 4(8), 29-33.

Karac1, A. ve Erdemir, M. (2017). Arduino ve Wifi Temelli Çok Sensörlü Robot Tasarımı ve Denetimi, Bilişim Teknolojileri Dergisi, 10(4), 435-442.

Ozan, E. (2020). Robotlar ve Uygulamaları, Yüksek Lisans Tezi, Batman Üniversitesi, Fen Bilimleri Enstitüsü, ElektrikElektronik Mühendisliği Ana Bilim Dalı, Batman.

Özdemir, D. ve Köse, C. (2008). Gezgin Robotların Çiftliklerde Ürün Yeri Belirleme ve Taşıma İşlemlerinde Kullanımı, EÜFBED Fen Bilimleri Enstitüsü Dergisi, 1(1), 49-60.

Postalcıŏlu, S. ve Köktürk, Ç. (2019). Bilgisayar Destekli DC Motor Hiz Denetimi, Erzincan Üniversitesi Fen Bilimleri Enstitüsü Dergisi, 12(2), 920-925.

Tezel, C. (2017). Elektrik Tahrikli Mobil Kontrollü Tank Robotun Tasarımı ve Gerçekleştirilmesi, Yüksek Lisans Tezi, Gelişim Üniversitesi, Fen Bilimleri Enstitüsü, Mekatronik Mühendisliği Ana Bilim Dalı, İstanbul.

Yılmaz, F. H. (2008). AC ve DC Servo Sistem Eğitim Setinin Gerçekleştirilmesi, Yüksek Lisans Tezi, Selçuk Üniversitesi, Fen Bilimleri Enstitüsü, Elektrik- Elektronik Mühendisliği Ana Bilim Dalı, Konya. 